\title{
Influence of Temperature-Driven Phenology and Photoperiodic Induction of Reproductive Diapause on Population Dynamics of Erythroneura comes (Homoptera: Cicadellidae)
}

\author{
TIMOTHY E. MARTINSON AND TIMOTHY J. DENNEHY1 \\ Department of Entomology, Cornell University, New York State Agricultural Experiment Station, \\ Geneva, NY 14456
}

\begin{abstract}
Environ. Entomol. 24(6): 1504-1514 (1995)
ABSTRACT The influence of degree-day accumulations and photoperiodic induction of diapause on the phenology of Erythroneura comes (Say) was investigated. In growth chamber experiments, nymphs reared at photoperiods of $<13.5: 10.5$ (L:D) $h$ entered reproductive diapause. Egg production and proportions of gravid females in field populations dropped sharply between 1 and 15 August in both the warm (1991) and cool (1992) growing seasons, suggesting that the onset of reproductive diapause occurs in late July to early August. Stage-specific developmental times from a 1912 study of 118 leafhopper nymphs were used to estimate degree-day requirements (base $10^{\circ} \mathrm{C}$ ) for eggs and the 5 nymphal stadia. These estimates were used to construct a stage-specific developmental model, which was validated with field data collected at 4 vineyards in 1991 and 1992. The model predictions agreed well with the timing of developmental events in 4 vineyards in both 1991 and 1992, years representing extremes in temperature accumulations in western and central New York. These data suggest that accumulations of $>710$ degree days (DD) before 1 August are required to produce a 2 nd generation of $E$. comes under climatic conditions in New York. Variations in temperature-driven development are hypothesized to strongly influence year-to-year variability in leafhopper abundance. Degree-day accumulations by 30 June correlated well with degree-days by 1 August and may provide a useful early-warning system for predicting years in which leafhopper population densities are above average.
\end{abstract}

KEY WORDS Erythroneura comes, phenology model, diapause, grapes, pest management

FROM THE LATE 1940s through the mid-1980s, routine insecticide applications based on calendar date and vine phenology relegated eastern grape leafhopper, Erythroneura comes (Say) to the status of a minor pest that was incidentally controlled by insecticide applications directed at the grape berry moth, Endopiza viteana Clemens (Taschenberg 1973). Recent adoption of integrated pest management (IPM) practices such as Grape Berry Moth Risk Assessment (Martinson et al. 1991) and pheromone mating disruption (Dennehy et al. 1991) by grape growers in New York and Pennsylvania has reduced pesticide inputs directed at grape berry moth and led to reemergence of this pest as an economic concern, prompting an interest in factors influencing its population ecology and management.

Historically, E. comes was considered to be the most important and devastating pest of 'Concord' Vitis labruscana Bailey grapes, particularly in the lake Erie region of New York, Ontario, and Penn-

\footnotetext{
1 Current address: Department of Entomology, University of Arizona, Tucson, AZ 85721.
}

sylvania (Slingerland 1904, Johnson 1914, Eyer 1931, Taschenberg and Hartzell 1949). From the late 1800 s to the 1940 s, observers noted that leafhopper outbreaks tended to occur in cycles of 2$3 \mathrm{yr}$, followed by several years in which populations failed to reach economically important levels except locally (Johnson 1914, Eyer 1931, Taschenberg and Hartzell 1949).

The life cycle of $\boldsymbol{E}$. comes suggests that these variations in year-to-year abundance early in the century may have been governed by temperaturedriven shifts in phenology, coupled with early onset of reproductive diapause. $E$. comes overwinters in the adult stage in border areas and enters vineyards shortly after budbreak. After completing postdiapause development, overwintered adults enter into an extended oviposition period lasting up to $8 \mathrm{wk}$ (Johnson 1914), producing a 1st brood of nymphs. Because of a relatively extended developmental time for eggs and nymphs, adults of the 1st brood typically begin appearing only in mid-July. Early lst-brood adults become reproductively mature and oviposit from late July through late August (Johnson 1914). However, Johnson's 
(1914) detailed observations of leafhopper phenology showed that nymphs maturing after 27 July entered into reproductive diapause. This early onset of reproductive diapause means that the time between appearance of reproductively active 1stbrood adults and the onset of reproductive diapause is short. Thus, small shifts in phenology associated with variability in temperature accumulations could greatly influence the size of the $2 \mathrm{nd}$ brood and the amount of late-season injury. Predicting temporal occurrence of leafhopper oviposition and nymphal development would be useful in pest management, not only for timing sampling and intervention, but also for assessing the risk that late-season population growth would cause economic injury.

We describe a phenology model that uses thermal unit accumulations and photoperiodic induction of diapause to predict timing of leafhopper population development. We first report experiments in which the timing of reproductive diapause initiation was estimated. We then use data from Johnson's (1914) observations of leafhopper phenology in 1912 to estimate degree-day accumulations necessary for stage-specific development. We then compare predictions from the phenology model with field data collected in 1991 and 1992. Finally, we use the model to explore the relationship between temperature accumulations and late-season population dymamics.

\section{Materials and Methods}

Laboratory Photoperiod Experiments. Potted 'Concord' vines with 6-10 leaves were placed for 24 $h$ within a laboratory colony of reproductively active $E$. comes for oviposition. This colony of $\approx 100$ adults had been reared for 1 generation at $21 \pm 2^{\circ} \mathrm{C}$ and a photoperiod of 16:8 (L:D) h. Each plant, infested with <24-h-old eggs, was removed from the colony, and placed within reach-in environmental chambers (Percival, Boone, IA) maintained at $21^{\circ} \mathrm{C}$, with photoperiods of $16: 8,14.5: 9.5,13.5: 10.5$, or 12:12 (L: D) h. Five separate cohorts of eggs were established in the chambers with $16: 8$ and 12:12 (L:D) h photoperiods and 3 cohorts of eggs were established in the chambers with $13.5: 10.5$ and $14.5: 9.5(\mathrm{~L}: \mathrm{D}) \mathrm{h}$ photoperiods between 1 June and 24 July, 1991. Leafhoppers were reared to adulthood in the chambers. Five to $8 \mathrm{~d}$ after molting to adults, leafhoppers were aspirated into vials, and pairs of male and female leafhoppers were transferred to mesh-covered clip cages ( $6.5 \mathrm{~cm}$ diameter, $3.5 \mathrm{~cm}$ deep). The clip cages were attached to leaves of potted Concord vines, with leafhoppers on the abaxial leaf surface. Five to 20 pairs of leafhoppers were established from each cohort. Plants with 5-7 clip cages were then placed in a rearing room at $21 \pm 2^{\circ} \mathrm{C}$ and 16 : 8 (L:D) h. After 7-10 d, cages and leaves were removed from the vines and checked for the presence of live leafhoppers. Units in which the female was alive were retained, and those with dead females were discarded. Leaves were cleared for $24 \mathrm{~h}$ in $95 \%$ ethyl alcohol, and eggs were counted. The proportion of units with eggs and the mean ( $\pm S D$ ) number of eggs per day were calculated using data pooled from all cohorts.

Field Oviposition Experiment. Adult leafhoppers or 5th-instar nymphs were collected in the field weekly from late July to late August, placed in clip cages, and allowed to feed and oviposit for $14 \mathrm{~d}$. Leafhoppers were collected from Concord vines with an aspirator and placed (in groups of 10) into mesh-covered clip cages $(6.5 \mathrm{~cm}$ diameter, $3.5 \mathrm{~cm}$ deep) on the abaxial side of Concord leaves with no visible feeding injury. Ten to 20 clip cages were set up on each date. In 1991, clip cages with 5th-instar nymphs were set up weekly from 29 July to $3 \mathrm{Sep}-$ tember, and cages with adults were set up from 29 July to 10 September. In 1992, cages of adults were set up on 13 July, 27 July, and weekly thereafter until 31 August. After $14 \mathrm{~d}$, leaves and cages were removed from vines and brought to the laboratory, where the numbers of live males, dead males, live females, and dead females were counted. Leaves were placed in $95 \%$ ethyl alcohol for $24 \mathrm{~h}$ to clear them, and eggs were counted. Proportions of cages with leafhopper eggs and the mean number of eggs per female per day were calculated for each sampling date.

Reproductive Status of $\boldsymbol{E}$. comes Females. Adult $E$. comes were collected weekly from a vineyard near Geneva, NY, during 1992 and 1993 and dissected to determine their reproductive status. Collections were made from 1 May through 3 September in 1992. In 1993, collections were made from 7 July to 15 September. On each sampling date, leafhoppers were collected with gasoline-powered leaf vacuums (Homelite, Charlotte, NC), and transferred to vials containing $70 \%$ ethyl alcohol for preservation and later processing. Twenty females were randomly selected from each sample and dissected to determine their ovarian development. Females were classified as gravid if at least one fully developed egg with clearly visible chorion was present, or nongravid if no eggs were visible. Thus, these dissections were able to distinguish between gravid and nongravid females, which could be either prereproductive females or females that were in reproductive diapause. Proportions of gravid females and $95 \% \mathrm{CI}$ based on binomial sampling error were calculated for each sampling date. Expected proportions of gravid and nongravid females were calculated from simulations made with the phenology model (described below), using 1992 and 1993 weather data, and were compared with observed proportions.

Phenology Model Structure. The phenology model simulates development and reproduction of a population of $E$. comes over the course of a growing season, as affected by temperature and diapause induction. The time steps of the model are in degree-days (base $10^{\circ} \mathrm{C}$ ), and simulations are based on minimum and maximum daily temperatures col- 
lected at field sites. A conversion table is used to convert cumulative degree days to Julian dates.

The duration of each developmental stage (eggs, nymphs, adults) is modeled using distributed delays (Manetsch 1976). Distributed delays use 2 parameters, $d e l$ and $k$, to simulate both the mean and variance of time-consuming processes. The parameter del is the mean time spent in a delay. The parameter $k$ (an integer) denotes the order of differential equations describing the rate at which individuals complete the delay. The variance of time spent completing a particular process in the delay is equal to $\mathrm{del}^{2} / k$.

The model starts with overwintered adults. These adults, after a specified temperature accumulation (128 DD, base $10^{\circ} \mathrm{C}$ ) is reached, complete their post-diapause development and enter into the 1st distributed delay. The 1st delay describes the mean longevity of ovenwintering adults after they become reproductively mature. Oviposition by adults in this stage is modeled as a function of temperature accumulations. The rate of oviposition is assumed to be temperature dependent, but relatively constant throughout the life span of $E$. comes adults, as found by Johnson (1914) and Cate (1975) in his studies of Erythroneura elegantula Osborn in California.

The eggs produced by these adults then feed directly into successive delays modeling developmental time in degree-days for each of the 5 nymphal instars. After passing through the 5th-instar delay, individuals enter a delay representing the preovipositional period of adult females. Adults then either become reproductively mature and generate eggs which again pass through developmental delays, or they enter into reproductive diapause and do not produce any eggs. The timing of this switch is triggered by a specific calendar date. This models the assumption that diapause induction is controlled by day length, and that individuals entering adulthood after a specific date are in reproductive diapause. Diapause induction probably occurs at some point during nymphal development (Cate 1975); however the model makes no assumptions about when this occurs.

Model Parameters. Temperature accumulations were based on a developmental threshold of $10^{\circ} \mathrm{C}$. This developmental threshold has not been determined experimentally, but corresponds well with that determined by Cate (1975) for E. elegantula. Cumulative degree-days were calculated starting 1 April, which is the earliest time at which temperatures above the thermal minimum occur under New York climatic conditions.

Estimates of stage-specific temperature accumulations required for development (Table 1) were derived from data presented by Johnson (1914). In that study, Johnson reports detailed observations of developmental times of eggs and all nymphal stages, as well as longevity and fecundity of adults. These observations included starting and ending dates for all developmental stages of 114 individual nymphs and cohorts of eggs $(n=312)$ deposited during sev-
Table 1. Parameters used to model stage-specific development (degree-days above $10^{\circ} \mathrm{C}$ ) of $E$. comes

\begin{tabular}{lrc}
\hline \hline \multicolumn{1}{c}{ Developmental stage } & $\begin{array}{c}\text { Degree-days } \\
\pm \text { SD }^{a}\end{array}$ & $k^{b}$ \\
\hline Egg & $208 \pm 63$ & 10 \\
Nymph & & \\
1st instar & $57 \pm 13$ & 19 \\
2nd instar & $46 \pm 13$ & 12 \\
3rd instar & $45 \pm 11$ & 17 \\
4th instar & $53 \pm 12$ & 19 \\
5th instar & $88 \pm 14$ & 39 \\
Total & $287 \pm 27$ & - \\
Adult & & \\
Postdiapause development & $128 \pm 28^{c}$ & 21 \\
Preovipositional period & $83 \pm 17^{c}$ & 24 \\
Avg length of ovipositional period & $333 \pm 111^{c}$ & 10 \\
Date of diapause induction & 1 August & \\
\hline
\end{tabular}

a Estimates based on data on developmental time of individual leafhopper eggs $(n=312)$ or nymphs $(n=116)$ (Johnson 1914). ${ }^{b}$ Parameter denoting the order of differential equations used in simulation model to model variance of developmental time.

${ }^{c}$ Estimates based on descriptive data.

eral 24-h periods. Using these starting and ending dates along with weather data also reported in Johnson (1914), we were able to estimate developmental time in degree-days for individual eggs and each of the 5 nymphal instars. From these degree-day estimates, we calculated mean ( \pm SD) developmental time in degree-days (base $10^{\circ} \mathrm{C}$ ), which are shown in Table 1.

Certain parameters, such as adult longevity in degree-days, and thermal accumulations required for preovipositional development, were not reported in detail by Johnson (1914). However, we assumed a preovipositional period (at a constant temperature of $\left.21^{\circ} \mathrm{C}\right)$ of $7 \mathrm{~d}(83 \pm 17 \mathrm{DD})$, and a $30-\mathrm{d}(333 \pm$ 111 DD) life span of reproductive females, based on observational data (Johnson 1914).

Stage-Specific Development in Field Populations in 1991 and 1992. To validate the temperature-driven phenology model, we made stage-specific counts of $E$. comes at 4 Concord vineyards in central and western New York during 1991 and 1992. These 2 growing seasons represented extremes from prevailing climatic conditions. In 1991, 1611 DD (14\% above average) were recorded over the course of the growing season. In 1992, 1236 DD (13\% below the long-term average) accumulated. In 1991, stage-specific nymphal counts were made at 2 vineyards in the Lake Erie region (Rammelt and Westwind) and at 2 in central New York (Erickson and Robbins Farm). In 1992, data were collected at 3 Lake Erie vineyards (Rammelt, Westwinds, and the Vineyard Laboratory) and 1 central New York vineyard (Erickson). At each of these vineyards, 20leaf samples were collected and brought to the laboratory, where counts of each nymphal instar were made under dissecting microscopes. Each vineyard was sampled from 1 June through 30 September. Samples were taken twice weekly until early-instar nymphs were detected, and weekly thereafter. Tem- 
perature data was collected at weather stations located $<5 \mathrm{~km}$ from each vineyard. Stage-specific counts from each week were then examined, and data for each nymphal instar were separated into lst- and 2nd-generation trends by finding the lowest number sampled between 2 successive population peaks. For most sites, this division was clear from examination of the data. However, during the cool 1992 season at Vineyard laboratory, Rammelt, and Westwind, separation of the 2 generations was somewhat more subjective because of an extended midseason period with low counts. At Erickson in 1992, only 1 distinct population peak was observed.

Weekly sample counts for each nymphal instar were converted to cumulative proportions of the total number sampled in each brood to provide a common scale for comparing observed population trends with those predicted by the phenology model. For each sample date, cumulative proportion $\left(p_{j k}\right)$ of weekly stage-specific counts $\left(c_{i j}\right)$ over the course of the growing season ( $n$ samples taken) by sthe $k^{\text {th }}$ sample date were calculated for each developmental stage $j$, using the following formula:

$$
p_{j k}=\frac{\sum_{i=1}^{k} c_{i j}}{\sum_{i=1}^{n} c_{i j}}
$$

Similar proportions were calculated from predictions generated from the phenology model, using temperature data from 1991 and 1992 for each vineyard site. Cumulative proportions from the field data and model predictions were compared by plotting cumulative proportions (observed and predicted) against calendar date for each site and year.

Degree-Day Accumulations and Late-Season Population Growth. To determine how year-toyear variability in temperature accumulations in New York growing regions might influence late-season population dynamics, simulations were run using $30 \mathrm{yr}$ of weather data from the 1963-1993 growing seasons in western and central New York, Data for western New York were taken from a weather station at the Vineyard laboratory in Fredonia, NY. For central New York, data were taken from the N.Y. State Agricultural Experiment Station at Geneva. For each simulation, the parameters previously described (Table 1) were used. The number of lst-broad leafhoppers entering diapause (maturing after 1 August) and the number becoming reproductively mature (maturing before 1 August) were recorded. From these simulation results, the percentage of lst-brood adults in diapause was calculated as a function of degree-day accumulations by 1 August. For each simulation, the total number of 1st- and 2nd-brood nymphs produced in the simulation was recorded. The ratio of 2 nd-brood to lst brood adult leafhoppers at the end of the season (1 October) was then calculated as a function of degree-day accumulations by 1 August. The model assumed that mortality factors acting on the nymphal
Table 2. Oviposition of $E$. comes reared from egge at different photoperiods

\begin{tabular}{cccc}
\hline $\begin{array}{c}\text { Photo- } \\
\text { period, } \\
\text { (L:D) } h\end{array}$ & $\begin{array}{c}\text { No. } \\
\text { pairs }\end{array}$ & $\begin{array}{c}\text { Eggs per pair/d } \\
\pm \text { SEM }\end{array}$ & $\begin{array}{c}\text { Proportion of } \\
\text { pairs with eggs } \\
\pm \text { SEM }\end{array}$ \\
\hline $12: 12$ & 42 & $0.00 \pm 0.00$ & $0.02 \pm 0.02^{a}$ \\
$13.5: 10.5$ & 41 & $0.00 \pm 0.00$ & $0.00 \pm 0.00$ \\
$14.5: 9.5$ & 28 & $0.1 .1 \pm 0.05$ & $0.36 \pm 0.09$ \\
$16: 08$ & 43 & $0.57 \pm 0.12$ & $0.63 \pm 0.07$ \\
\hline
\end{tabular}

${ }^{a}$ One egg was found in 1 cage.

and adult population were constant throughout the growing season.

Degree-day accumulations by 30 June and 1 August were also recorded, and 1 August degree-days were regressed on 30 June degree-days, to determine whether degree-day accumulations at the onset of reproductive diapause could be predicted accurately by degree-day accumulations in midJune.

\section{Results}

Laboratory Photoperiod Experiments. Rearing leafhoppers at different photoperiods ranging from 16:8 to $12: 12$ (L:D) $h$ influenced both the mean number of eggs per pair and the proportion of pairs with eggs (Table 2). Sixty-five percent of pairs reared with a 16-h photophase produced an average of 0.57 eggs per day. Only $35 \%$ of pairs reared at 14.5:9.5 (L:D) h oviposited, and the mean number of eggs per pair per day dropped to 0.11. Leafhoppers reared at photophases of $<13.5 \mathrm{~h}$ did not oviposit. This experiment demonstrated that photoperiod is associated with the onset of reproductive diapause in $E$. comes, as is the case with the closely related western grape leafhopper $E$. elegantula (Cate 1975).

Field Oviposition Experiment. In both the 1991 and 1992 experiments that measured oviposition of field populations of $E$. comes, oviposition as measured by changes in the mean number of eggs oviposited per adult per week began to decline between the last week in July and the 1st wk of August (Fig. $1 \mathrm{C}-\mathrm{E}$ ). In 1991, eggs per female per cage dropped from $0.9 / \mathrm{d}$ for individuals caged on 29 July to $0.2 / \mathrm{d}$ for those caged on 6 August. No further oviposition was observed in cohorts caged on $27 \mathrm{Au}$ gust or later. Fifth-instar nymphs caged during the same weekly intervals produced eggs only on 29 July, and none thereafter (Fig. 1A). In 1992, the rate of oviposition per female declined more gradually (Fig. 1E). Cohorts caged on 27 July produced 1.3 eggs per female per day. Cohorts caged on the following week (3 August) produced an average of 0.5 eggs per day. The rate of oviposition declined thereafter until 24 August, after which no oviposition was noted. In both years, representing dramatically different degree-day accumulations, oviposition ceased by 24-27 August. 

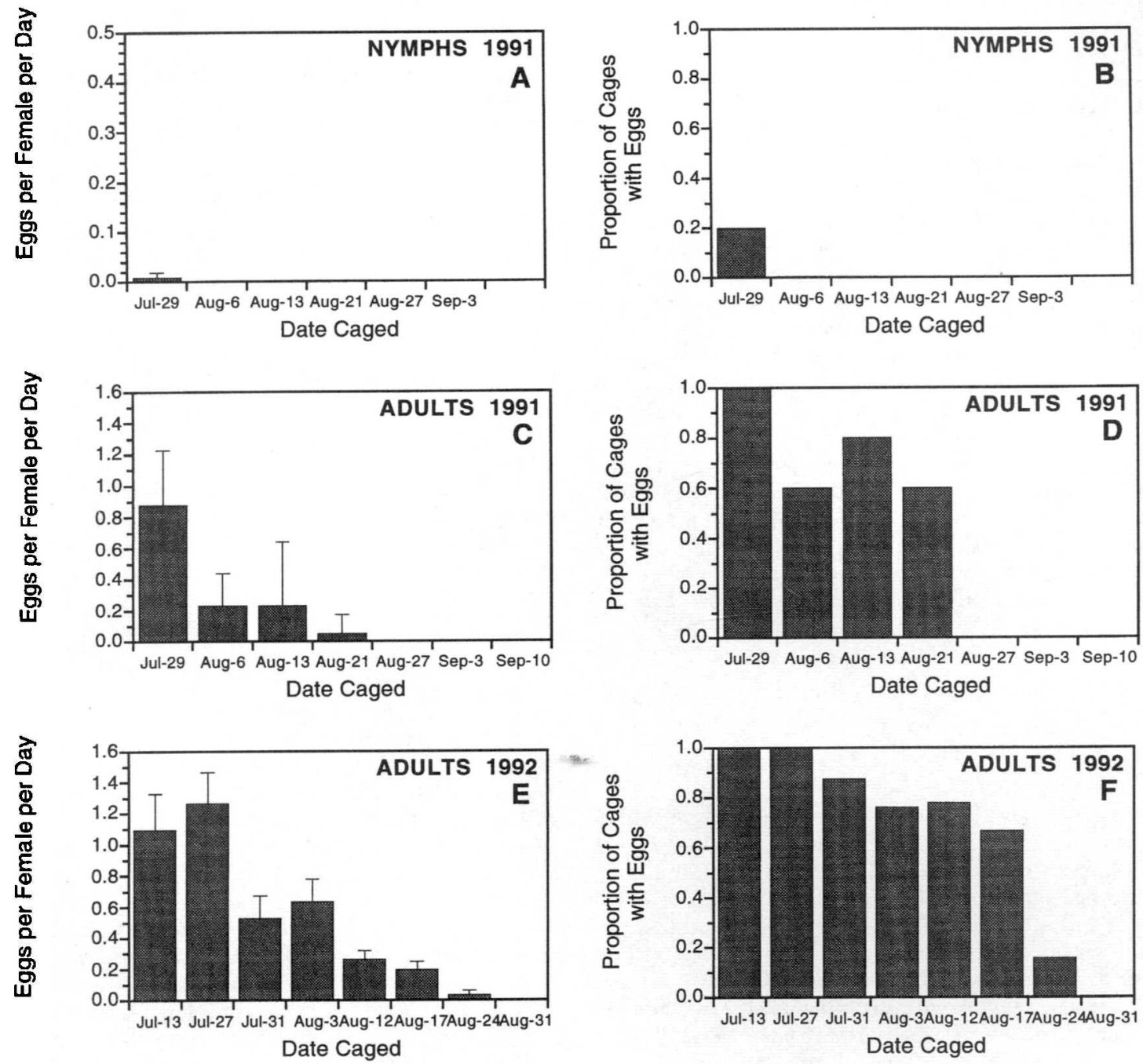

Fig. 1. Oviposition by cohorts of $E$. comes sampled from field populations and confined for $14 \mathrm{~d}$ in clip cages. Oviposition rates $(A, C, E)$ and proportion of cages with $\geq 1$ egg $(B, D, F ; n=10-20$ cages per date) are shown.

The probable entry of diapausing females into the population is also indicated by changes in the proportion of experimental units in which eggs were detected (Fig. 1 B, D, and F). Because each unit had a cohort of 2-8 females confined for $14 \mathrm{~d}$, absence of oviposition probably indicated that all females in the cages were in reproductive diapause. In 1991, eggs were detected in all of the 29 July units (Fig. 1D). On the next sample date (6 August), we detected eggs in only $60 \%$ of the sample units. Similarly, in 1992, we found eggs in $100 \%$ of the units from the 13 July and 27 July cohorts (Fig. 1F). Starting with the 31 July cohort, however, the proportion of units in which eggs were found declined gradually through mid-August.

These patterns are consistent with the entry of females in diapause into the population starting between the last week in July and the lst wk in August. Because females were not individually caged, we were not able to demonstrate whether the overall decline in egg production per female was caused by lower output per reproductive female or the result of steadily declining proportions of reproductive (nondiapause) females in the population from which we were sampling. However, the gradual decline in oviposition rates and in the proportion of units with eggs is consistent with survivorship of early-maturing females through late August and with an increasing proportion of diapausing females in the population starting in early August. Failure of 5thinstar nymphs caged after 6 August to oviposit (Fig. 1B) supports the hypothesis that leafhoppers molting to adulthood after early August entered reproductive diapause.

Reproductive Status of $\boldsymbol{E}$. comes Females. In 1992 , the proportion of gravid females rose sharply in early June following postdiapause development of overwintered females. It remained at $100 \%$ 

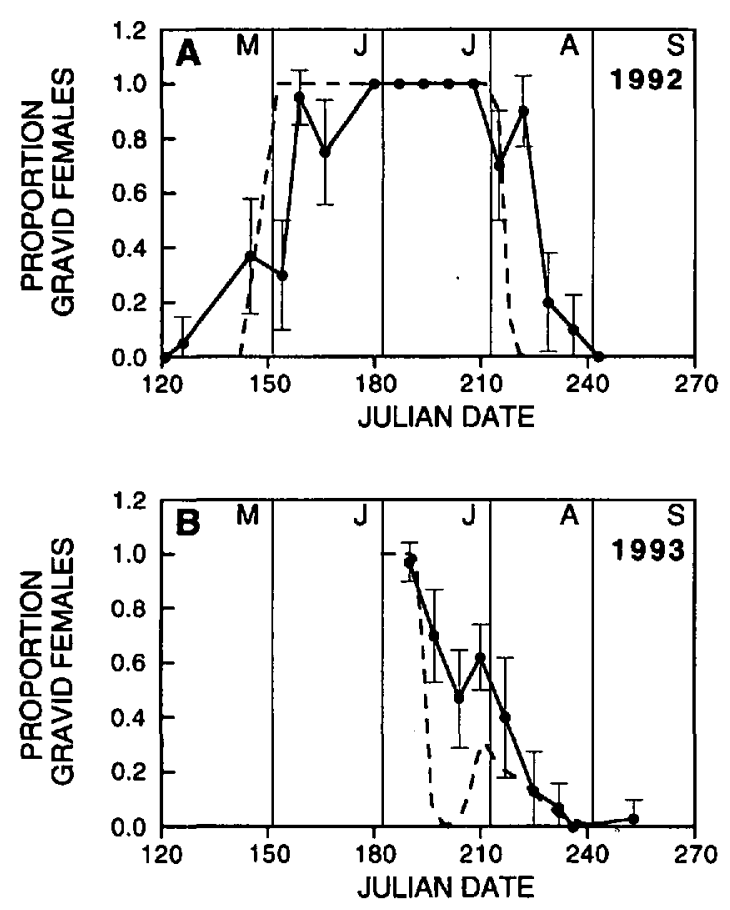

Fig. 2. Proportion of gravid $E$. comes females in field populations in 1992 (A) and 1993 (B), determined by dissection. Solid lines indicate proportion $( \pm 95 \%$ binomial confidence interval) observed; dashed lines indicate expected proportions determined through simulation.

through late June and July, and began to decline after the 27 July sampling period (Fig. 2A). Proportions of gravid females rose between the $3 \mathrm{Au}-$ gust and 10 August samples and subsequently declined sharply through late August. In 1993, decline in the proportion of gravid females started in midJuly, and proceeded more gradually than in 1992 (Fig 2B). After declining in mid-July, proportions rose briefly on 27 July and declined thereafter through late August.

Trends in these data were consistent with those of the field oviposition experiment (Fig. 1), and also suggest that the onset of reproductive diapause occurs in late July to early August. It is important to note that our dissections distinguished only gravid from nongravid females. Our population of nongravid females undoubtedly comprised varying mixtures of prereproductive females that subsequently became gravid, and diapausing females. The difference in trends between 1992 and 1993 probably reflects differences in degree-day accumulations among the $2 \mathrm{yr}$ that slowed population development in 1992. In 1992, lst-brood adults did not begin to appear until the end of July. Thus the 1992 trend probably reflected progressive increases in proportions of females that had entered reproductive diapause. In 1993, 1st-brood adults began to appear in the 2nd wk in July. The earlier, more gradual decline in proportions of gravid females was probably caused by entrance into the population of prereproductive females that later would become gravid.

Phenology Model and Observed Phenology. Observed population trends corresponded well with predicted population trends derived from the phenology model (Figs. 3 and 4). In 1991, temperature accumulations through 1 October were 1,531 DD (base $10^{\circ} \mathrm{C}$ ) in central New York, and 1,611 DD in western New York, $15 \%$ above average. As a result of unseasonably warm temperatures in May and June, development of nymphs was accelerated in comparison with other years. However, predictions from the phenology model for both 1st- and 2ndbrood nymphs corresponded closely with observed population trends at Rammelt, Robbins, and Erickson (Fig. 3 D-L). At Westwind, observed trends were consistently shifted earlier than those predicted by the model (Fig. $3 \mathrm{~A}-\mathrm{C}$ ). Particularly for $2 \mathrm{nd}-$ generation nymphal counts, observed trends were $\approx 14 \mathrm{~d}$ earlier than predicted trends. We attribute this discrepancy between observed and predicted trends to environmental conditions at the experiment site. This vineyard, planted in soils with low water-holding capacity, was subjected to severe moisture stress caused by low rainfall from midJune through harvest. We hypothesize that the water stress resulted in increasingly severe mortality of all life stages as the growing season progressed. As a result, egg, nymphal, and adult population densities were reduced in the latter part of the growing season relative to the early part of the season. This heavy mortality would shift the observed cumulative proportions of nymphal populations to earlier in the season, resulting in apparently earlier phenology than that predicted by the model. In the remaining vineyards in both central and western New York, timing of cumulative frequency of instar-specific densities was predicted closely by the model.

In 1992, seasonal thermal unit accumulations were 1,054 in central New York and 1,236 in the Lake Erie region, $\approx 15 \%$ below average degree-day accumulations. However, during 1992, the predicted 1st-generation population trends also closely agreed with observed trends (Fig. $4 \mathrm{~A}-\mathrm{J}$ ) in both central and westem New York. Predictions for 2ndbrood population trends were more variable. We believe this in large part to be because the 2nd generation, though distinctly observable in western New York vineyards, was very small. Furthermore, not all individuals in either the simulation or field sampling had completed development by $30 \mathrm{Sep}-$ tember, which was the termination date for both the model and field sampling. Notably, differences in cumulative degree-days in central and western New York were substantial, and the model correctly predicted a single generation for the central New York vineyard, and a small 2nd generation in the 3 Lake Erie vineyards.

Predicted Timing of $E$. comes Development. Thermal unit accumulations required for leafhopper development and average dates at which these accumulations occur in the central New York and 

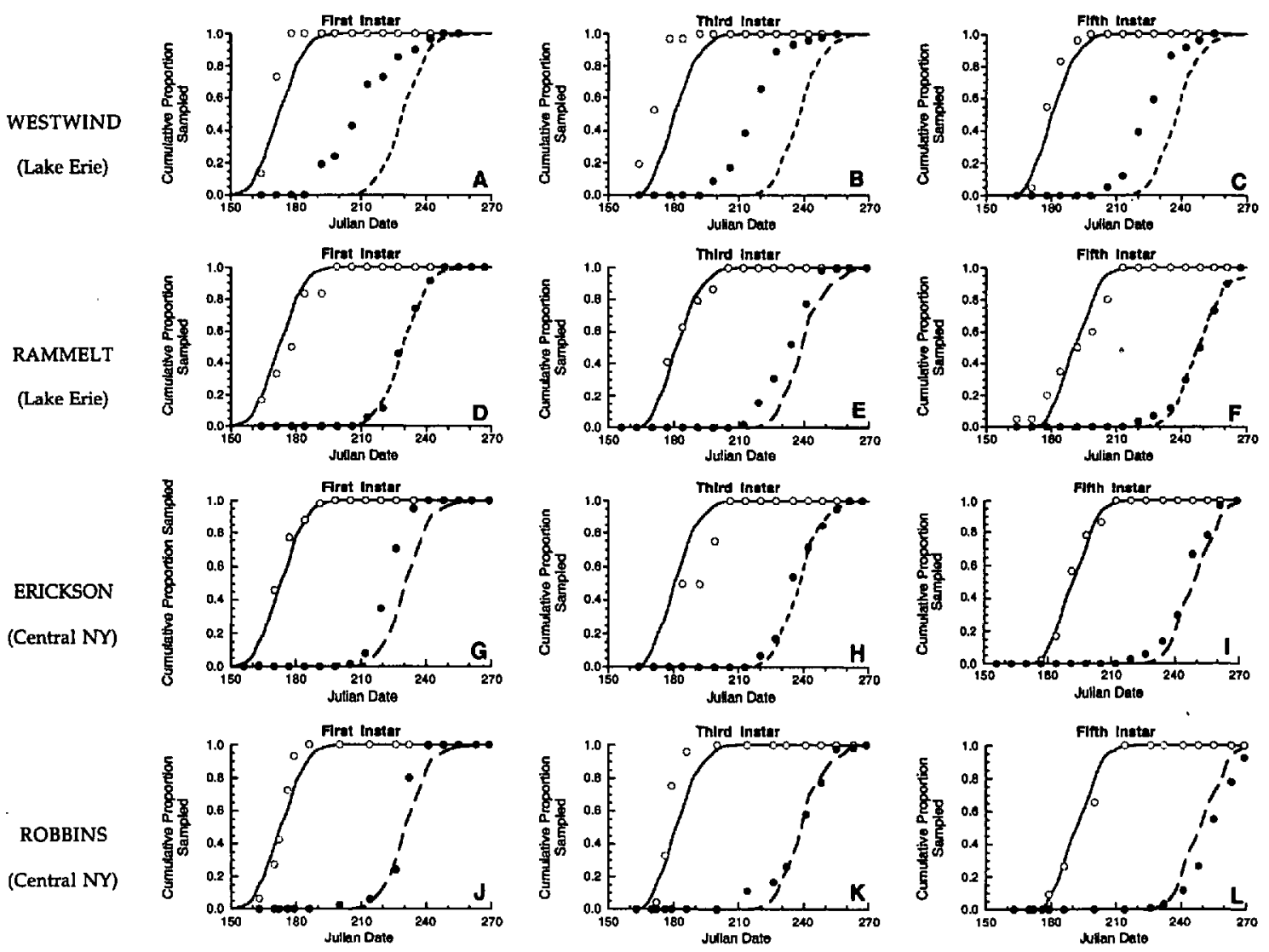

Fig. 3. Comparison of observed and predicted cumulative proportions of 1st-, 3rd-, and 5th-instar E. comes nymphs observed in 4 vineyards in 1991. Lines indicate cumulative proportions of 1st-brood (solid lines) and 2 nd-brood (dashed lines) nymphs predicted through simulation. Observed cumulative proportions of 1st-brood (open circles) and 2nd-brood (shaded circles) nymphs are shown.

Lake Erie growing regions are shown in Table 3. Degree-day accumulations by 1 August average 851 \pm 77 in the Lake Erie region, but only $792 \pm 69$ in central New York. As a result, dates predicted for completion of developmental stages in central New York lagged 5-10 d behind those of Lake Erie. Notable was the fact that the timing of adult emergence was extremely close to the hypothesized 1 August date for initiation of reproductive diapause. The model predicted that $10 \%$ of 1 st-brood nymphs would enter adulthood by 29 July (central New York) or 25 July (western New York), only 2-7 d before the hypothesized initiation of reproductive diapause. Thus, it is clear that in seasons with average temperature accumulations, a large proportion of 1st-brood E. comes enter into reproductive diapause.

Degree-Day Accumulations and Late-Season Population Growth. Simulations run with weather data from 1963 to 1993 showed substantial variation in degree-day accumulations by 1 August (Fig 5A). Degree-day accumulations ranged from 615 to 1,005 in central New York and from 710 to 1,300 in the Lake Erie region. Over the range of $30 \mathrm{yr}$, degree-day accumulations averaged $\approx 50 \mathrm{DD}$ less in central New York than in the Lake Erie region. Notably, these data indicate that years with $<760 \mathrm{DD}$, which would result in $>90 \%$ of 1stbrood adults entering into reproductive diapause, occurred $35 \%$ of the time in central New York but only $10 \%$ of the time in western New York. At the other extreme, years with $>890 \mathrm{DD}$ by 1 August occurred $30 \%$ of the time in western New York, but only $5 \%$ of the time in central New York. According to model predictions, $>50 \%$ of 1 st-brood adults would become reproductively active under these conditions. In both regions, however, about the same proportion of years $(55 \%$ in western New York and $60 \%$ in central New York) had degreeday accumulations between 760 and $890 \mathrm{DD}$ by 1 August, which would result in $50-90 \%$ of adults entering into reproductive diapause.

The potential effect of variation in the proportion of 1st-brood adults entering diapause was assessed by calculating the ratio of 2nd-brood leafhoppers to lst-brood leafhoppers under prevailing degree-day accumulations (Fig. 5B). With low temperature accumulations $(<760 \mathrm{DD})$, the potential population increase was $<5: 1$; with average accumulations $(760-890 \mathrm{DD})$, the potential ratio 

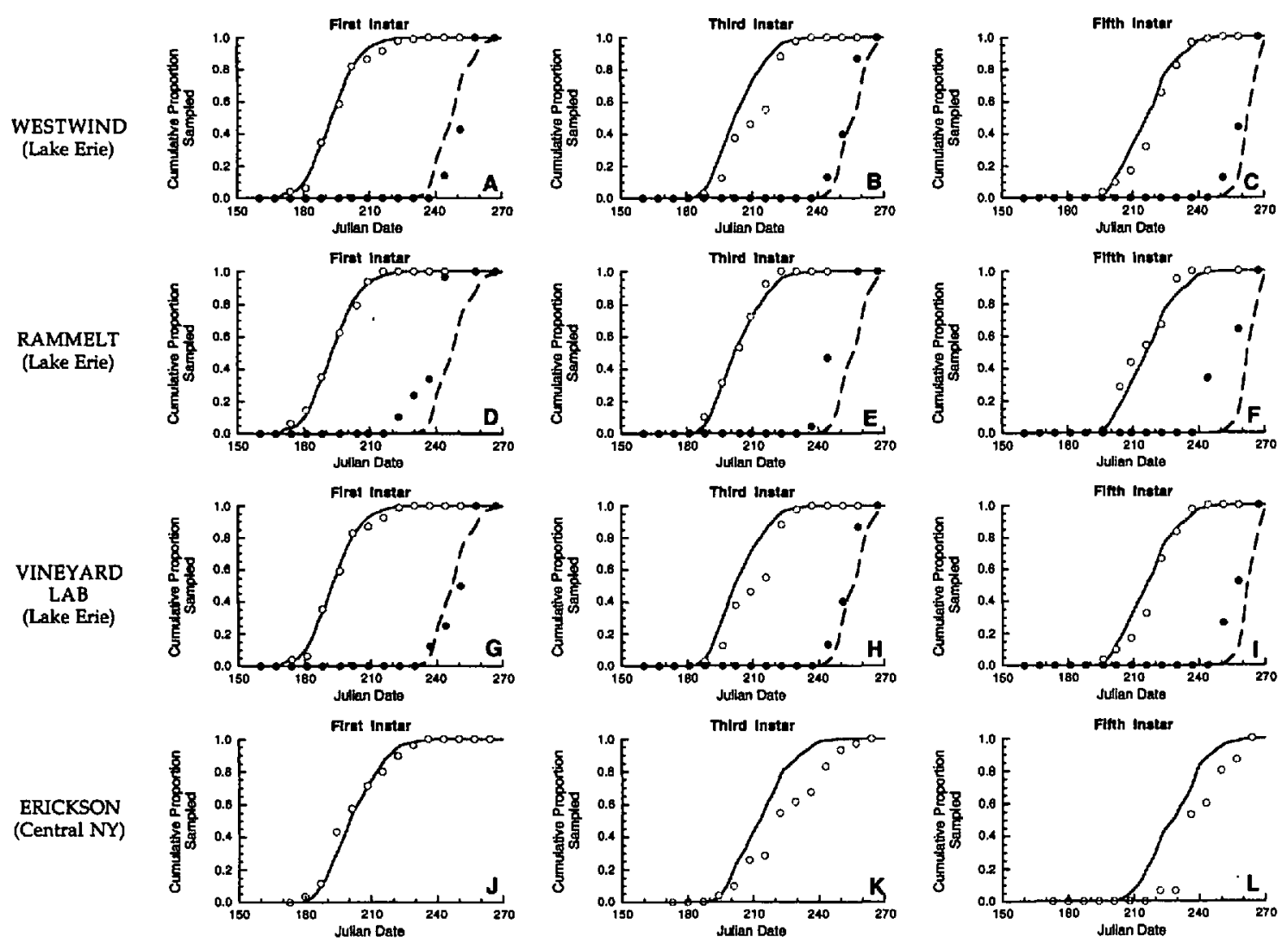

Fig. 4. Comparison of observed and predicted cumulative proportions of 1st-, 3rd-, and 5th-instar E. comes nymphs observed in 4 vineyards in 1992. Lines indicate cumulative proportions of 1st-brood (solid lines) and 2nd-brood (dashed lines) nymphs predicted through simulation. Observed cumulative proportions of lst-brood (open circles) and 2nd-brood (shaded circles) nymphs are shown.

Table 3. Model predictions of degree-day accumulations for completion of $E$. comes development and average date at which degree-day accumulations occur in central New York and Lake Erie growing regions

\begin{tabular}{|c|c|c|c|c|c|c|c|}
\hline \multirow{3}{*}{ Parameter } & \multirow{3}{*}{ Stage } & \multicolumn{6}{|c|}{ Cumulative $\%$ of brood in stage } \\
\hline & & \multicolumn{3}{|c|}{ lst brood } & \multicolumn{3}{|c|}{ 2nd brood } \\
\hline & & $10 \%$ & $50 \%$ & $90 \%$ & $10 \%$ & $50 \%$ & $90 \%$ \\
\hline Degree-days $s^{a}$ & $\begin{array}{l}\text { Egg } \\
\text { 1st instar } \\
5 \text { th instar } \\
\text { Nymph } \\
\text { Adult }\end{array}$ & $\begin{array}{l}250 \\
403 \\
611 \\
472 \\
761\end{array}$ & $\begin{array}{l}389 \\
528 \\
750 \\
653 \\
889\end{array}$ & $\begin{array}{r}556 \\
667 \\
889 \\
819 \\
1,028\end{array}$ & $\begin{array}{r}917 \\
1,056 \\
1,264 \\
1,139 \\
1,292\end{array}$ & $\begin{array}{l}1,506 \\
1,194 \\
1,389 \\
1,306 \\
1,403\end{array}$ & $\begin{array}{l}1,222 \\
1,333 \\
1,486 \\
1,458 \\
1,486\end{array}$ \\
\hline Avg date in central N.Y. ${ }^{c}$ & $\begin{array}{l}\text { Egg } \\
\text { 1st instar } \\
\text { 5th instar } \\
\text { Nymph } \\
\text { Adult }\end{array}$ & $\begin{array}{l}11 \text { June } \\
27 \text { June } \\
16 \text { July } \\
5 \text { July } \\
29 \text { July }\end{array}$ & $\begin{array}{l}26 \text { June } \\
9 \text { July } \\
28 \text { July } \\
20 \text { July } \\
10 \text { Aug. }\end{array}$ & $\begin{array}{l}12 \text { July } \\
21 \text { July } \\
10 \text { Aug. } \\
3 \text { Aug. } \\
24 \text { Aug. }\end{array}$ & $\begin{array}{c}13 \text { Aug. } \\
27 \text { Aug. } \\
26 \text { Sept. } \\
5 \text { Sept. } \\
1 \text { Oct. }\end{array}$ & $\begin{array}{l}27 \text { Aug. } \\
12 \text { Sept. } \\
- \\
-\end{array}$ & $\begin{array}{l}19 \text { Sept } \\
- \\
- \\
-\end{array}$ \\
\hline Avg date in western N.Y.d & $\begin{array}{l}\text { Egg } \\
\text { 1st instar } \\
\text { 5th instar } \\
\text { Nymph }^{b} \\
\text { Adult }\end{array}$ & $\begin{array}{l}7 \text { June } \\
22 \text { June } \\
11 \text { July } \\
29 \text { June } \\
24 \text { July }\end{array}$ & $\begin{array}{l}21 \text { June } \\
4 \text { July } \\
22 \text { July } \\
14 \text { July } \\
3 \text { Aug. }\end{array}$ & $\begin{array}{l}6 \text { July } \\
15 \text { July } \\
3 \text { Aug. } \\
28 \text { July } \\
15 \text { Aug. }\end{array}$ & $\begin{array}{l}5 \text { Aug. } \\
17 \text { Aug. } \\
8 \text { Sept. } \\
26 \text { Aug. } \\
10 \text { Sept. }\end{array}$ & $\begin{array}{l}17 \text { Aug. } \\
31 \text { Aug. } \\
25 \text { Sept. } \\
12 \text { Sept. } \\
26 \text { Sept. }\end{array}$ & $\begin{array}{l}4 \text { Sept } \\
17 \text { Sept } \\
-\quad \\
-1 \text { Oct. }\end{array}$ \\
\hline
\end{tabular}

a Base $10^{\circ} \mathrm{C}$

${ }^{b}$ All instars.

c Based on weather data from 1963 to 1993 at N.Y. State Agricultural Experiment Station, Geneva.

${ }^{d}$ Based on weather data from 1963 to 1993 at E. F. Taschenberg Vineyard Laboratory, Fredonia, NY. 

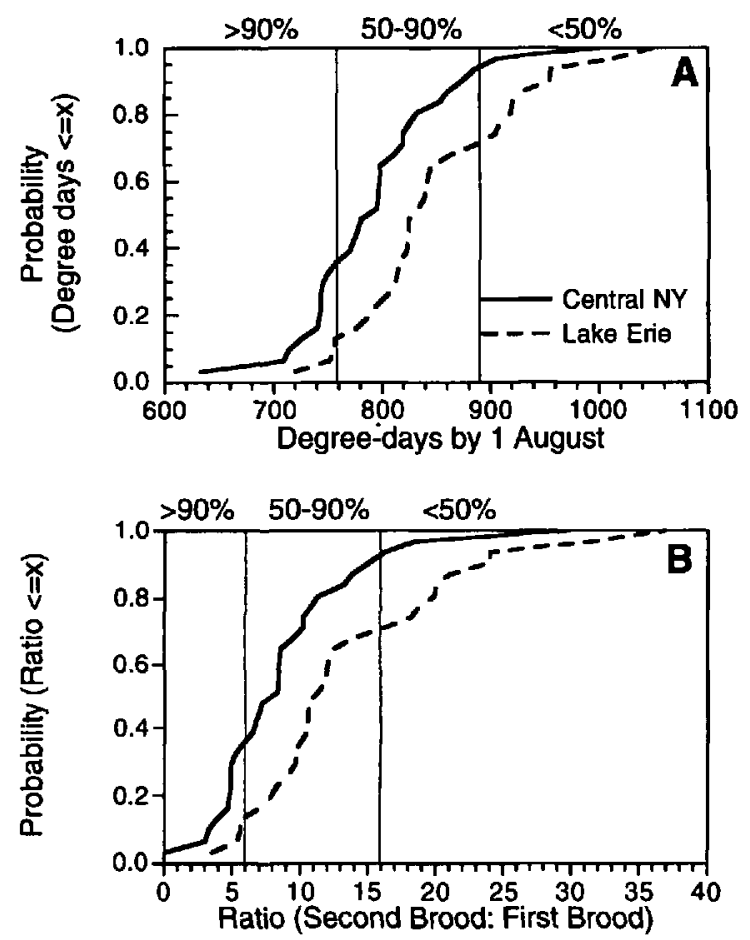

Fig. 5. (A) Cumulative distribution of degree-day (base $10^{\circ} \mathrm{C}$ ) accumulations by 1 August derived from 1963-1993 weather data at Fredonia (Lake Erie region) and Geneva (central New York), New York. (B) Predicted maximum ratio of 2 nd-brood to 1 st-brood $E$. comes. Numbers at top indicate expected proportions of 1stbrood $E$. comes entering reproductive diapause.

of 2 nd-brood to 1st-brood leafhoppers was between 5:1 and 16:1. In years with >890 DD, however, the ratio ranged from $16: 1$ to $35: 1$.

\section{Discussion}

We have shown that a simple model based on field-collected data from 1912 was able to accurately predict the timing of population development of $E$. comes in 2 growing regions in New York during 1991 and 1992. The 2 major assumptions of the model are that (1) the rate of development is linearly related to temperature, and that (2) 1stbrood adults emerging before a specific date ( 1 August) become reproductively active, whereas those maturing after the date enter reproductive diapause. These assumptions undoubtedly simplify how these 2 factors function in influencing phenology and population dynamics. Nevertheless, they were able to accurately predict seasonal timing of instar-specific development in 2 growing seasons representing extremes in temperature accumulations under New York climatic conditions, except in 1 vineyard with severe water stress (Fig. $3 \mathrm{~A}-\mathrm{C}$ ). We therefore believe that this model, although simplistic, provides a good foundation for evaluating how temperature influences late-season population dynamics and for predicting timing of population development for pest management purposes.

The model clearly demonstrates that only a small fraction of 1st-brood $E$. comes completes development in time to become reproductively mature and produce a 2nd brood in New York. Total developmental time, from egg to egg, requires an average of $623 \mathrm{DD}$. With postdiapause development of overwintered adults included, we estimate that at least $710 \mathrm{DD}$ are required to produce reproductively active 1st-brood adults. Our experimental evidence, and that of Johnson (1914), indicates that diapause induction occurs between the last few days in July and the 1st wk of August. Therefore, an important factor limiting potential population growth in New York conditions is the relatively short time between the appearance of 1st-brood adults and the onset of reproductive diapause around 1 August. Average accumulations of 792 (central New York) to 861 (Lake Erie) DD by this date suggest that in average years, between 60 and $75 \%$ of 1 st-brood adults enter reproductive diapause.

The short period between maturation of early 1st-brood adults and the photoperiodic-mediated initiation of diapause, however, suggests that the potential size of the 2 nd brood can vary tremendously with small changes in degree-day accumulations that accelerate or delay development. Examination of year-to-year variability in weather data suggests that $>90 \%$ of 1 st-brood $E$. comes enter reproductive diapause in $10 \%$ (Lake Erie) to $35 \%$ (central New York) of the years. In these years, the potential for late-season population growth and subsequent heavy foliar injury would be low. At the other extreme, in 5\% (central New York) to $30 \%$ (western New York) of the past 30 $\mathrm{yr}$, the expected proportion of 2nd-brood adults in reproductive diapause was $<50 \%$. Under these conditions, the potential for rapid late-season population growth and severe foliar injury would be great.

We examined degree-day accumulations by 1 August from Erie, PA, between 1900 and 1925, during which 3 outbreak periods (1901-1904, 1909-1912, and 1921-1925) were reported to have occurred in the Lake Erie region (Slingerland 1904, Hartzell 1912, Johnson 1914, Eyer 1931). Results (Fig. 6) show that during each leafhopper outbreak, degree-day accumulations well in excess of 760 occurred during the year preceding or the 1st yr of the reported outbreak. Although other factors (notably low amounts of rainfall during the early part of the growing season) (Eyer 1931) were hypothesized to be associated with outbreaks, it is likely that higher-than-average thermal accumulations were a major factor associated with the onset of these outbreaks.

As growers in New York adopt IPM practices that have greatly reduced the application of routine insecticide sprays to vineyards, a major con- 


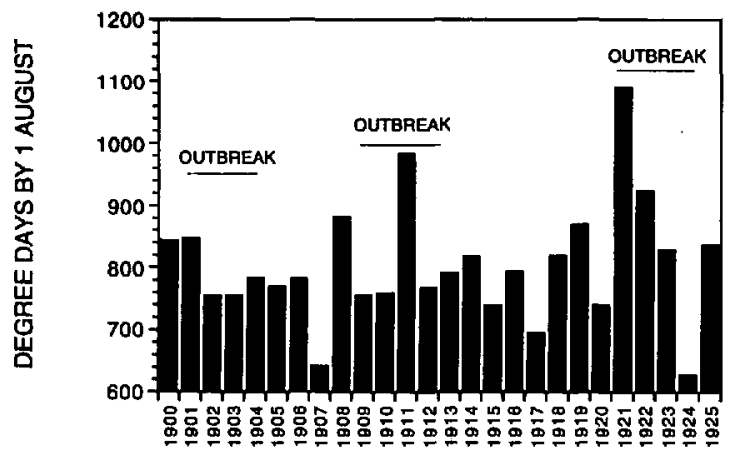

Fig. 6. Degree-day accumulations by 1 August at Erie, $P A$, from 1900 to 1925 , during which 3 leafhopper outbreaks (1901-1904, 1909-1912, and 1921-1925) were reported by Johnson (1914), Hartzell (1912) and Eyer (1931).

cern has been that leafhoppers, which were previously controlled by sprays applied for other pests, would again become a major concern. Our studies of leafhopper population dynamics suggest, however, that leafhoppers do not reach economically significant population densities in most vineyards during normal years. Recent surveys of leafhopper population densities in vineyards without insecticide treatments (Martinson et al. 1994) showed that seasonal population densities exceeded the proposed threshold level of 5 nymphs per leaf in only $2-25 \%$ of vineyards surveyed from 19891992. Results of our simulations suggest that temperature accumulations permitting only a small, partial 2nd generation in most years are a major factor limiting population growth. Therefore, areawide, economically significant leafhopper infestations are likely to be common only in years with above-average degree-day accumulations. The historical data indicate that these conditions occur only in $1-3$ yr in 10 under New York climatic conditions. The limiting effect of temperature also provides a clear rationale for avoiding routine insecticide sprays directed at suppressing leafhoppers, except possibly in extremely hot years.

Degree-day estimates of $E$. comes phenology provided by this simulation model will provide useful information for management of this pest in New York. Phenology predictions (Table 3) can be used to time sampling and to assess the need for insecticide applications. Timing sampling at $\approx 650$ DD, midway in leafhopper nymphal development (Table 3), would in most cases allow assessment of peak 1st-brood nymphal populations and intervention before significant foliar injury became apparent.

Equally important, evaluation of degree-day accumulations during the early part of the growing season may be useful in assessing the risk of large, damaging 2 nd-brood populations later in the season. Much of the variability in degree-day accumulations occurs during the months of May and

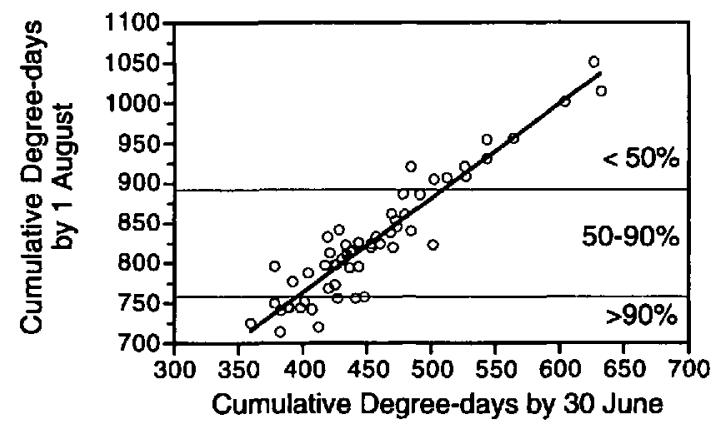

Fig. 7. Correlation of cumulative degree-days on 30 June and 1 August. Percentages indicate expected proportions of 1st-brood $E$. comes entering reproductive diapause. Regression equation is $y=291+1.19 x r^{2}=0.88$.

June. Degree-days by 30 June correlate well with degree-days by 1 August (Fig. 7, degree-day 1 . August $=291+1.19$ (degree-day 15 June), $r^{2}=$ 0.88 ). Therefore, the degree-day accumulations by 30 June could serve as a predictor of the risk of damaging late-season population growth and allow appropriate early intervention in years when temperature accumulations indicated a large 2 nd brood was probable.

\section{Acknowledgments}

We thank Jan Nyrop (Cornell University) and Greg English-Loeb (Cornell University) for reviewing the manuscript. Rick Dunst, Ted Taft, Jr., Steve Lefko, and Sara Martini (Cornell University) assisted with the field work. This work was funded, in part, by the New York Wine and Grape Foundation and Grape Production Research Fund, and the Sustainable Agriculture Research and Education Grants Program of the USDA.

\section{References Cited}

Cate, J. R. 1975. Ecology of Erythroneura elegantula Osborn (Homoptera: Cicadellidae) in grape agroecosystems in California. Ph.D. dissertation, University of California, Berkeley.

Dennehy, T. J., L. G. Clark, and J. S. Kamas. 1991. Pheromonal control of the grape berry moth: an effective alternative to conventional insecticides. New York's Food and Life Sci. Bull. 135.

Eyer, J. R. 1931. The relation of temperature and rainfall to outbreaks of the grape leafhopper, Erythroneura comes Say. Ann. Entomol. Soc. Am. 24: 238-259.

Hartzell, F. Z. 1912. The grape leafhopper and its control. N.Y. Agric. Exp. Stn. Geneva Bull. 344

Johnson, F. 1914. The grape leafhopper in the Lake Erie Valley. U.S. Dep. Agric. Bull. 19.

Jubb, G. L., Jr., L. Danko, and C. W. Haeseler. 1983. Impact of Erythroneura comes Say (Homoptera: Cicadellidae) on caged 'Concord' grapevines. Environ. Entomol. 12: 1576-1580.

Manetseh, T. J. 1976. Time-varying distributed delays and their use in aggregative models of large systems. IEEE Transactions on Systems, Man and Cybernetics 6: $547-553$ 

Martinson, T. E., C. J. Hoffman, T. J. Dennehy, J. S.
Kamas, and T. Weigle. 1991. Risk assessment of grape berry moth and guidelines for management of the eastern grape leafhopper. New York's Food and Life Sci. Bull. 138.

Martinson, T. E., T. J. Dennehy, and C. J. Hoffman. 1994. Phenology, within-vineyard distribution, and seasonal movement of eastem grape leafhopper (Homoptera: Cicadellidae) in New York vineyards. Environ. Entomol. 23: 236-244.
Slingerland, M. V. 1904. The grape leafhopper. Cornell Univ. Agric. Exp. Stn. Bull. 215.

Taschenberg, E. F., and F. Z. Hartzell. 1949. Grape leafhopper control-1944 to 1947. N.Y. State Agric. Exp. Stn. Geneva Bull. 738.

Taschenberg, E. F. 1973. Economic status and control of grape leafhopper in western New York. Search Agric. (Geneva, NY). 3.

Received for publication 22 March 1995; accepted 11 July 1995. 